\title{
Severe thoracic trauma - still an independent predictor for death in multiple injured patients?
}

Michael Grubmüller, Maximilian Kerschbaum, Eva Diepold, Katharina Angerpointner, Michael Nerlich and Antonio Ernstberger ${ }^{*}$

\begin{abstract}
Background: Over the past, the severe thoracic trauma has had decisive influence on the outcome of multiple injured patients. Today, new therapies (e.g. extracorporeal membrane oxygenation (ECMO), protective ventilation methods and new forms of patient positioning) are available and applied regularly. What impact on the patient's outcome does the thoracic trauma have today?
\end{abstract}

Methods: Prospective data collection of multiple injured patients in a level-I trauma center was performed between 2008 and 2014. Patients with an ISS $\geq 16$ were included and divided into 2 groups: Severe thoracic trauma (STT: AIS Thorax $\geq 3$ ) and mild thoracic trauma (MTT: AIS $_{\text {Thorax }}<3$ ). In addition to preclinical and trauma room care, detailed information about clinical course and outcome were assessed.

Results: In total, 529 patients (STT: $n=317 ;$ MTT: $n=212$ ) met the in- and exclusion criteria. The mean Injury Severity Score (ISS) was significantly higher in patients of the STT group (STT: 33.5 Vs. MTT: 24.7; $p<0.001$ ), while the RISC II Score showed no significant differences (ST: 20.0 vs. MTT: 17.1; $p=0.241$ ). Preclinical data revealed a higher intubation rate, more chest tube insertions and a higher use of catecholamines in the STT group $(p<0.05)$. Clinically, we found significant differences in the duration of invasive ventilation (STT: 7.3d vs. MTT: $5.4 \mathrm{~d} ; p=0.001$ ) and ICU stay (STT: 12.3d vs. MTT: 9.4d; $p<0.001$ ). While the complication rate was higher for the ST group (sepsis (STT: $11.4 \%$ vs. MTT: 5.7\%; $p=0.017$ ); lung failure (STT: $23.7 \%$ vs. MTT: $12.3 \% ; p=0,001)$ ), neither the non-adjusted lethality rate (STT: $13.2 \%$ vs. MTT: 13.7\%; $p=0.493$ ) nor the Standardized Mortality Ratio (SMR) showed significant differences (STT: 0.66 vs. MTT: 0.80; $p=0.397$ ). The multivariate regressive analysis confirmed that severe thoracic trauma is not an independent risk factor for lethality in our patient cohort.

Conclusion: Despite a higher injury severity, the extended need of emergency measures and a higher rate of complications in injured patients with severe blunt thoracic trauma, no influence on lethality can be proved. The reduction of the complication rate should be a goal for the next decades.

Keywords: Multiple trauma patient, Thoracic trauma, Severely injured patient, TraumaRegister, Polytrauma, Major Trauma

\footnotetext{
* Correspondence: toni.ernstberger@ukr.de

Department of Trauma Surgery, University Medical Center Regensburg,

Franz-Josef-Strauss-Allee 11, D-93053 Regensburg, Germany
} 


\section{Background}

Severe multiple trauma is one of the tenth most common causes of death worldwide [1]. More than $50 \%$ of all severely injured patients (Injury severity score (ISS $[2]) \geq 16)$ suffer a relevant thoracic trauma [3]. In the past, thoracic trauma was associated with a high lethality rate. Severe thoracic injuries were considered to be responsible for $25 \%$ of all trauma deaths [4]. Furthermore, the lethality of multiple injured patients who sustained a thoracic trauma was assessed to be significantly higher than in multiple injured patients of equal severity without a thoracic trauma $[5,6]$.

These circumstances led to a continuous development and improvement of thoracic injury treatment. Nowadays, lung-protective, non-invasive ventilation protocols and early extubation are used to avoid ventilation induced lung injuries [7]. Compared to former controlled mechanical ventilation regimes, the early use of spontaneous breathing ventilation modalities is associated with a shorter duration of ventilatory support and a reduced length of intensive care unit (ICU) stay [8]. Moreover, these non-invasive ventilation modalities are helpful in case of an acute respiratory distress syndrome (ARDS) caused by a thoracic trauma [9]. In addition to these ventilation modalities the use of an extracorporeal membrane oxygenation (ECMO) in event of an ARDS can improve the outcome of severely injured patients, even in circumstances such as a hemorrhagic shock or coagulation failure [10].

Beside these treatment concepts, there are other medical achievements, which can improve the outcome of patients with a thoracic trauma, e.g. modern operative stabilization techniques of flail thoracic injuries [11] or the renaissance of prone positioning in ARDS [12].

Nevertheless, despite the described improvements, it is unclear whether these modern therapeutic concepts can improve the survival rate of multiple trauma patients with thoracic trauma injuries.

Therefore, the aim of the present study was to evaluate if there are still differences concerning the clinical outcome and lethality in multiple injured patients with or without a severe thoracic trauma.

\section{Methods}

\section{Data collection}

Over a period of 7 years (01.01.2008-31.12.2014) 1403 patients, treated in our level-I trauma center, were recorded in the Trauma Register $\mathrm{DGU}^{\odot}$, the trauma registry of the German Trauma Society (DGU) [13]. Of this collective, patients over 16 years and with an ISS $\geq$ 16 were included in this study. Patients were excluded if they were transferred from or to an outside hospital, in the event of unsuccessful emergency resuscitation and with an Abbreviated Injury Scale (AIS [14]) Head of 6. Additionally, all patients who sustained a penetrating thoracic trauma were excluded. In total, 578 patients met the inclusion criteria. The data collection of 49 patients was incomplete, therefore the study population consists of 529 patients (Fig. 1).

In contrast to other countries, the German trauma care system represents a decentralized system. In addition to different structural requirements, a level-I trauma center must fulfil at least 40 admissions with an ISS $\geq 16$ [13, 15-17].

In total, about 500 parameters were collected prospectively in each single case during trauma room management by a study assistant. As well as the data of the TraumaRegister DGU $^{\bullet}$ standard questionnaire (150 parameters, www.traumaregister-dgu.de), 350 other variables were collected to gain further information about the preclinical and clinical trauma care. The TraumaRegister $\mathrm{DGU}^{\bullet}$ standard questionnaire contains parameters concerning demography, individual treatment steps and relevant trauma scores: Glasgow Coma Scale (GCS) [18], Abbreviated Injury Scale (AIS) [14], Injury Severity Score (ISS) [2], New Injury Severity Score NISS [19], Glasgow Outcome Scale (GOS) [20] and Revised Injury Severity Classification II (RISC II), a prognostic tool for lethality in multiple injured patients [21]. In the present study, RISC II was used to calculate the expected lethality rate and to compute the standardized mortality ratio (SMR), which is defined as the quotient of the observed to the expected mortality.

\section{Ethical considerations}

The study has been approved by the Institutional Review Board of the University of Regensburg (Number 14101-0004). Data anonymity is guaranteed.

\section{Statistical analysis}

A univariate data analysis was performed to compare patients with a severe thoracic trauma AIS $_{\text {Thorax }} \geq 3$,

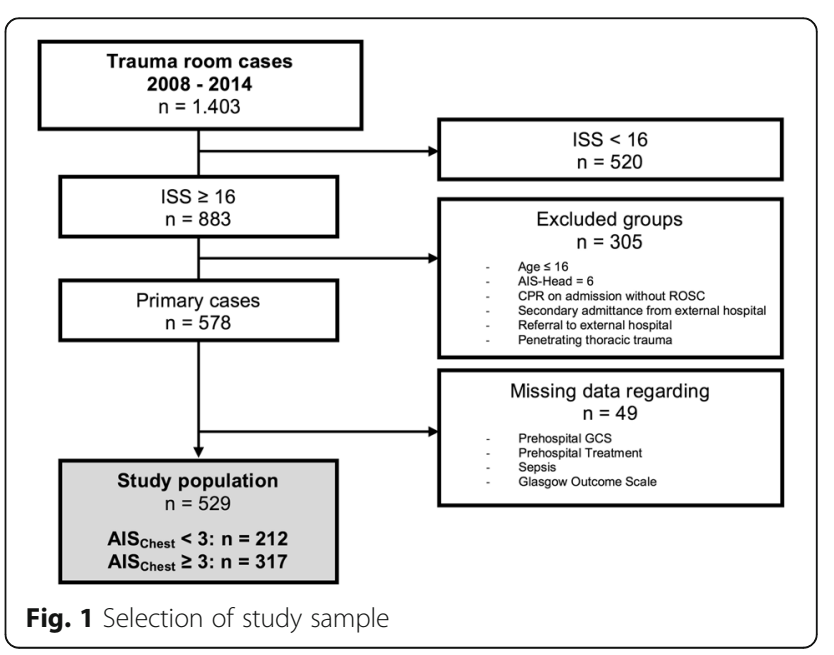


STT group, $n=317$ ) and a mild thoracic trauma (AIS Thorax $_{<3}$, MTT group, $n=212$ ). The Chi-SquareTest $\left(x^{2}\right.$-Test) was used to analyze binary or nominal target variables. Mann-Whitney U-Test was performed in ordinal or metric values.

Two logistic regression analyses with the target variable "death in hospital" followed.

Firstly: An exploration of multiple dichotomous influence factors (age $\geq 60$ yrs. vs. age $<60$ yrs.; first measured blood pressure on-scene $\geq 90 \mathrm{mmHg}$ vs. $<90 \mathrm{mmHg}$; Glasgow Coma Scale $<9$ vs. $\geq 9$; AIS $_{\text {Head }} \geq 3$ vs. $<3$; AIS $_{\text {Abdomen }} \geq 3$ vs. < 3 ; $\operatorname{AIS}_{\text {Extremities }} \geq 3$ vs. $<3$; AIS $_{\text {Thorax }} \geq 3$ vs. $<3$; Volume prehospital \& trauma room care $\geq 4000 \mathrm{ml} \mathrm{vs}$. $<4000 \mathrm{ml}$; Organ failure; Multiple organ failure).

Secondly: Influence of severely injured body parts on lethality (AIS $_{\text {Head }} \geq 3$ vs. $<3$; AIS $_{\text {Thorax }} \geq 3$ vs. $<3$; AIS $_{\mathrm{Ab}-}$ domen $\geq 3$ vs. $<3$; $\operatorname{AIS}_{\text {Extremities }} \geq 3$ vs. $<3$ ).

All influence factors were included in a logistic regression analysis (backward elimination). $P$-values and odds ratios (OR) for each factor were calculated as well as the corresponding $95 \%$ confidence intervals (CI).

The statistical analysis (level of significance, $p<0.05$ ) was carried out using SPSS software (SPSS Inc., Chicago, Illinois).

\section{Results}

\section{Demographic characteristics}

The STT group consists of 317 patients, the MTT group of 212 patients. The mean age was $44.8 \pm 21.1$ years; $73.3 \%$ of all included patients were male. No significant differences between the groups concerning age and sex could be identified. The mean ISS of all included patients was $30.0 \pm 11.7$, the mean NISS was $37.0 \pm 15.0$ with significant higher score values for the STT group compared to the MTT group $(p<0.001)$. The mean RISC II was $18.9 \pm 27.8$ with no significant differences between both groups. Different trauma mechanisms between the two groups could be identified. In the STT group we found a significantly higher rate of motor vehicle crashes as cause of injury, while low-height falls were more common in the MTT group (Table 1).

As well as the trauma mechanism both groups showed significant differences concerning the injury pattern. The STT group showed more severe abdominal and limb injuries. In contrast to that, severe brain injuries were more common in the MTT group. Despite the higher incidence of severe brain injuries in the MTT group, the preclinical GCS showed no significant differences.

On average, the presence of a severe thoracic trauma (STT group) was associated with a higher number of clinical diagnoses and operations (Table 1).

Table 1 Demographics, trauma scores and injury pattern

\begin{tabular}{|c|c|c|c|c|}
\hline & $\begin{array}{l}\text { Total } \\
n=529\end{array}$ & $\begin{array}{l}\text { STT } \\
\text { AIS Thorax } \geq 3 \\
n=317\end{array}$ & $\begin{array}{l}\text { MTT } \\
\text { AIS Thorax }<3 \\
n=212\end{array}$ & $P$-value \\
\hline \multicolumn{5}{|l|}{ Demographics and Trauma scores: } \\
\hline - Male (n / \%) & $388 / 73.3$ & $237 / 74.8$ & $151 / 71.2$ & 0.211 \\
\hline - Age (years \pm SD) & $44.8( \pm 21.1)$ & $43.9( \pm 20.7)$ & $46.1( \pm 21.6)$ & 0.260 \\
\hline - ISS ( $\varnothing \pm S D)$ & $30.0( \pm 11.7)$ & $33.5( \pm 12.8)$ & $24.7( \pm 7.1)$ & $<0.001$ \\
\hline - NISS $(\varnothing \pm S D)$ & $37.0( \pm 15.0)$ & $39.2( \pm 14.9)$ & $33.9( \pm 14.7)$ & $<0.001$ \\
\hline - RISC II ( $\varnothing \pm S D)$ & $18.9( \pm 27.8)$ & $20.0( \pm 29.0)$ & $17.1( \pm 25.8)$ & 0.241 \\
\hline - Prehospital GCS ( $\varnothing \pm \mathrm{SD})$ & $10.6( \pm 4.6)$ & $10.5( \pm 4.7)$ & $10.7( \pm 4.4)$ & 0.817 \\
\hline \multicolumn{5}{|l|}{ Concomitant injuries: } \\
\hline - AIS Head $\geq 3$ (n / \%) & $304 / 57.5$ & $153 / 48.3$ & $151 / 71.2$ & $<0.001$ \\
\hline - AIS Abdomen $\geq 3$ (n / \%) & $106 / 20.0$ & $78 / 24.6$ & $28 / 13.2$ & $<0.001$ \\
\hline - AIS Extremities $\geq 3$ ( $\mathrm{n} / \%)$ & $227 / 42.9$ & $138 / 43.5$ & $89 / 42.0$ & 0.396 \\
\hline - AIS Extremities $\geq 2$ (n / \%) & $384 / 72.6$ & $246 / 77.6$ & $138 / 65.1$ & 0.001 \\
\hline - Number of diagnoses $(\varnothing \pm S D)$ & $8.7( \pm 4.0)$ & $9.5( \pm 4.0)$ & $7.5( \pm 3.7)$ & $<0.001$ \\
\hline - Number of surgeries $(\varnothing \pm S D)$ & $5.4( \pm 5.7)$ & $5.8( \pm 6.2)$ & $4.7( \pm 4.8)$ & 0.021 \\
\hline \multicolumn{5}{|l|}{ Trauma mechanism: } \\
\hline - Motor vehicle accident (n / \%) & $286 / 54.1$ & $190 / 59.9$ & $96 / 45.3$ & 0.001 \\
\hline - Bicycle / Pedestrian (n / \%) & $67 / 12.7$ & $37 / 11.7$ & $30 / 14.2$ & 0.239 \\
\hline - Falls <3 m (n / \%) & $64 / 12.1$ & $24 / 7.6$ & $40 / 18.9$ & $<0.001$ \\
\hline - Falls >3 m (n / \%) & $76 / 14.4$ & $47 / 14.8$ & $29 / 13.7$ & 0.407 \\
\hline - Other (n / \%) & $36 / 6.8$ & $19 / 6.0$ & $17 / 8.0$ & 0.231 \\
\hline
\end{tabular}




\section{Preclinical care}

Regarding the preclinical trauma sequence, intubation rate, rate of chest tube insertions and requirement of catecholamines were significantly higher in the STT group compared to the MTT group. Hemodynamic instability (RR syst. $<90 \mathrm{mmHg}$ ) occurred more often in patients with a severe thoracic trauma (STT group). While no significant differences in the preclinical rescue time could be identified between both groups, air-rescue was more common in the STT group (Table 2).

\section{Trauma room care}

In patients of the STT group significantly lower hemoglobin values could be measured. However, there is no significant difference concerning massive transfusion of red blood cells (RBT $\geq 10$ units of packed red blood cells) and circulatory instability, with only a slightly higher occurrence in the STT group. In $28.4 \%$ of all patients with a severe thoracic trauma (STT) chest tube insertion was performed during trauma room care. In order to substitute large volumes during the trauma room period, arterial lines and central venous accesses, e.g. CVC/Shaldon, were more frequently indicated in patients with a severe thoracic trauma (STT). In both groups, it took about 25 min until the whole-bodymultislice-CT (WBMS-CT) was performed. No significant differences for the total trauma room time could be detected (Table 3).

\section{Outcome}

Significantly more complications such as sepsis, organ failure and respiratory failure occurred in the STT group. Only patients of the STT group were treated with an extracorporeal membrane oxygenation (ECMO) system. It should be noted, that the majority of ECMOpatients in our center got this treatment in peripheral hospitals by our air rescue ECMO-team and were then transferred. Because of this circumstance the majority of ECMO-patients were excluded. The duration of invasive ventilation and ICU stay, as well as the total hospital stay, was significantly longer in patients with a severe thoracic trauma (STT) compared to the MTT group (Table 4).

The overall mortality rate was $13.4 \%$ without significant differences between patients with a severe (STT) and a mild thoracic trauma (MTT). Moreover, no significant differences concerning the standardized mortality ratio (SMR) could be detected. In both groups about $70 \%$ of the survivors showed a "good outcome" (Glasgow Outcome Scale $\geq 4$ ) without significant differences.

\section{Logistic regression analysis}

The first multivariate analysis showed that the severe thoracic trauma is not an independent predictor of lethality $(p>0.05)$. In contrast, massive transfusion of red blood cells (RBT $\geq 10$ units of packed red blood cells) (OR 9.0; 95\%-CI 2.6-31.3), an age over 60 years (OR 7.5; 95\%-CI 4.0-14.0), GCS $<9$ (OR 6.2; 95\%-CI

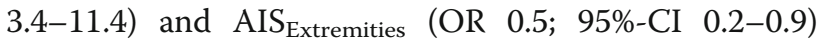
were identified as independent risk factors.

The second multivariate regression analysis concerning the injury pattern showed that head injuries (AISHead $\geq 3$ ) (OR 3.2; 95\%-CI 1.7-5.9) and abdominal injuries $\left(\mathrm{AIS}_{\mathrm{Abdomen}} \geq 3\right)(\mathrm{OR} 2.2$; 95\%-CI 1.2-4.1) were primary causes for death. The presence of a thoracic trauma had no influence on mortality.

\section{Discussion}

This study deals with the influence of a severe thoracic trauma on the overall outcome and lethality rate of multiple injured patients.

In contrast to previously published investigations $[5,6]$ we could demonstrate for our population, that a severe thoracic trauma has no influence on the mortality rate and is no independent predictor for death in multiple injured patients.

Similar to previously published data [22-24], motor vehicle crashes could be identified as the most frequent injury mechanism for developing a severe thoracic trauma. Although, no significant difference of age between the two groups could be confirmed, low-height falls, as injury mechanism were much more common in

Table 2 Preclinical sequence and interventions

\begin{tabular}{|c|c|c|c|c|}
\hline & $\begin{array}{l}\text { Total } \\
n=529\end{array}$ & $\begin{array}{l}\text { STT } \\
\text { AIS Thorax } \geq 3 \\
n=317\end{array}$ & $\begin{array}{l}\text { MTT } \\
\text { AIS Thorax }<3 \\
n=212\end{array}$ & $P$-value \\
\hline Air-rescue (n / \%) & $350 / 66.2$ & $221 / 69.7$ & $129 / 60.8$ & 0.022 \\
\hline Rescue time $(\min \pm \mathrm{SD})$ & $88.2( \pm 52.5)$ & $86.5( \pm 47.0)$ & $90.7( \pm 59.6)$ & 0.964 \\
\hline Preclinical RR < 90 mmHg (n / \%) & $87 / 16.4$ & $62 / 19.6$ & $25 / 11.8$ & 0.012 \\
\hline Preclinical intubation (n / \%) & $308 / 58.2$ & $202 / 63.7$ & $106 / 50.0$ & 0.001 \\
\hline Preclinical chest tube ( $\mathrm{n} / \%)$ & $71 / 13.4$ & $67 / 21.1$ & $4 / 1.9$ & $<0.001$ \\
\hline Preclinical CPR (n / \%) & $14 / 2.6$ & $11 / 3.5$ & $3 / 1.4$ & 0.120 \\
\hline Preclinical catecholamine (n / \%) & $115 / 21.7$ & $83 / 26.2$ & $32 / 15.1$ & 0.002 \\
\hline
\end{tabular}


Table 3 Interventions and data of trauma room care

\begin{tabular}{|c|c|c|c|c|}
\hline & $\begin{array}{l}\text { Total } \\
n=529\end{array}$ & $\begin{array}{l}\text { STT } \\
\text { AIS Thorax } \geq 3 \\
n=317\end{array}$ & $\begin{array}{l}\text { MTT } \\
\text { AIS Thorax }<3 \\
n=212\end{array}$ & $P$-value \\
\hline Trauma room intubation (n / \%) & $58 / 11.0$ & $31 / 9.8$ & $27 / 12.7$ & 0.177 \\
\hline Trauma room chest tube (n / \%) & 99 / 18.7 & $90 / 28.4$ & $9 / 4.2$ & $<0.001$ \\
\hline Trauma room CPR (n / \%) & $3 / 0.6$ & $3 / 0.9$ & $0 / 0.0$ & 0.214 \\
\hline Trauma room catecholamine (n / \%) & $278 / 52.6$ & $179 / 56.5$ & 99 / 46.7 & 0.017 \\
\hline CVC / Shaldon (n / \%) & $186 / 35.2$ & $128 / 40.4$ & $58 / 27.4$ & 0.001 \\
\hline Arterial line (n / \%) & $345 / 65.2$ & $226 / 71.3$ & $119 / 56.1$ & $<0.001$ \\
\hline $\mathrm{RR}<90 \mathrm{mmHg}$ trauma room & $74 / 14.0$ & $51 / 16.1$ & $23 / 10.8$ & 0.056 \\
\hline Hemoglobin concentration $\mathrm{g} / \mathrm{dl}(\varnothing \pm \mathrm{SD})$ & $12.2( \pm 2.7)$ & $11.9( \pm 2.8)$ & $12.6( \pm 2.5)$ & 0.004 \\
\hline Hemoglobin concentration < $9 \mathrm{~g} / \mathrm{dl}(\mathrm{n} / \%)$ & $63 / 12.0$ & $42 / 13.6$ & $20 / 9.5$ & 0.100 \\
\hline RBT >10 units ( $\mathrm{n} / \%)$ & $21 / 4.0$ & $16 / 5.0$ & $5 / 2.4$ & 0.090 \\
\hline Whole-Body-Multislice-CT (WBMS-CT) (n / \%) & $506 / 95.7$ & $309 / 97.5$ & $197 / 92.9$ & 0.011 \\
\hline Minutes until WBMS $-C T(\min \pm S D)$ & $25.3( \pm 11.5)$ & $25.9( \pm 12.9)$ & $24.2( \pm 9.0)$ & 0.312 \\
\hline Total length of trauma room care $(\min \pm S D)$ & $67.4( \pm 34.5)$ & $68.4( \pm 33.9)$ & $65.8( \pm 35.5)$ & 0.312 \\
\hline
\end{tabular}

the MTT group with a higher rate of traumatic brain injuries. Patients, who suffered a severe thoracic trauma (STT) showed a higher ISS compared to the other patients (MTT). Similar findings are published by Hill et al. [23].

Previous investigations showed a correlation between ISS and the mortality rate of multiple injured patients [25]. However, despite a higher ISS in the STT group, we could not find a higher mortality rate in these patients. This circumstance shows, that scoring systems that consider both, anatomic injury severity and physiologic parameters are potentially more qualified to predict lethality.

The preclinical time period in our collective was higher (88 min.) than the national average (69 min.) [3].
One reason could be the higher rate of air rescue transports $(66.2 \%$ vs. national average: $40.2 \%)$ [3]. Nevertheless, Kleber et al. showed that the preclinical time period has no influence on the overall lethality rate of multiple injured patients [26].

Especially patients with a severe thoracic trauma showed a higher rate of preclinical procedures (e.g. intubation: $63.7 \%$; chest tube insertion: $21.1 \%$ ) compared to the national average [3] or previously published data [27]. Bayer et al. also observed a higher rate of preclinical procedures in patients with a severe thoracic trauma compared to patients without (intubation: $44 \%$ vs. $36.3 \%$; chest tube insertion: $11 \%$ vs. $1.9 \%$ ] [22]. However, compared to the data of Bayer et al., the preclinical procedure rate was higher in our collective. This could be

Table 4 Outcome indicators

\begin{tabular}{|c|c|c|c|c|}
\hline & $\begin{array}{l}\text { Total } \\
n=529\end{array}$ & $\begin{array}{l}\text { STT } \\
\text { AIS Thorax } \geq 3 \\
n=317\end{array}$ & $\begin{array}{l}\text { MTT } \\
\text { AIS Thorax }<3 \\
n=212\end{array}$ & $P$-value \\
\hline Organ failure (n / \%) & $344 / 65.0$ & $221 / 69.7$ & $123 / 58.0$ & 0.004 \\
\hline Organ failure lungs (n / \%) & $101 / 19.1$ & $75 / 23.7$ & $26 / 12.3$ & 0.001 \\
\hline $\mathrm{ECMO}(\mathrm{n} / \%)$ & $9 / 1.7$ & $9 / 2.8$ & $0 / 0.0$ & 0.010 \\
\hline Multi-organ failure (n / \%) & $207 / 39.1$ & $133 / 42.0$ & $74 / 34.9$ & 0.062 \\
\hline Sepsis (n / \%) & $48 / 9.1$ & $36 / 11.4$ & $12 / 5.7$ & 0.017 \\
\hline Thromboembolic event (n / \%) & $29 / 5.5$ & $20 / 6.3$ & $9 / 4.2$ & 0.497 \\
\hline Length of intubation days ( $\varnothing \pm S D$ ) & $6.6( \pm 8.7)$ & $7.3( \pm 8.7)$ & $5.4( \pm 8.7)$ & 0.001 \\
\hline Length of stay on ICU days ( $\varnothing \pm S D$ ) & $11.1( \pm 11.7)$ & $12.3( \pm 11.6)$ & $9.4( \pm 11.7)$ & $<0.001$ \\
\hline Length of stay in hospital days ( $\varnothing \pm \mathrm{SD}$ ) & $21.0( \pm 15.4)$ & $22.1( \pm 16.0)$ & $19.4( \pm 14.3)$ & 0.049 \\
\hline Mortality (n / \%) & $71 / 13.4$ & $42 / 13.2$ & $29 / 13.7$ & 0.493 \\
\hline Standardized Mortality Ratio (SMR) & 0.71 & 0.66 & 0.80 & 0.397 \\
\hline Glasgow Outcome Scale $\geq 4$ (n / \%) & $368 / 69.6$ & $224 / 70.7$ & 144 / 67.9 & 0.289 \\
\hline
\end{tabular}


explained by a higher injury severity of our patient cohort (mean ISS: 30.0 vs. 25.6) or a higher rate of preclinical procedures in air rescue transport, demonstrated by Andruszkow et al. [28].

Patients who suffered a severe thoracic trauma showed a significantly extended period of invasive respiration (mean 7 days) and length of ICU stay (mean 12 days) compared to patients with a mild thoracic trauma. These findings are comparable with previously published data (invasive respiration: 7d; ICU: 11d [29]; invasive respiration: 8d; ICU: 11d [27]). Additionally, the complication rate (e.g. organ failure, respiratory failure, sepsis) was higher in the STT group compared to the MTT group. Whereas Trupka et al. reported that patients with a thoracic trauma are significantly more likely to develop multiple organ failure [30], we could not find differences between both groups.

Over the last decades a decline of lethality in trauma patients could be observed [31, 32]. Previous studies presented considerably higher lethality rates in patients who suffered a thoracic trauma $(7.6 \%($ ISS $=16.4)$ [33]; $18.7 \%($ ISS $=26.7)$ [34] $)$.

In contrast to prior studies [5,6] our study shows no further influence of thoracic trauma to lethality in multiple injured patients. The lethality in our study $(13.2 \%$ (STT) vs. $13.7 \%$ (MTT)) is lower than the lethality rates of other German multicenter studies (Timm et al. 17\%, SMR 0.82 [3], Huber et al. 17.5\% [29]). This could be due to the high case load of our trauma center $(>100 /$ year). Zacher et al. [35] come to the conclusion that the hospital volume is as an independent predictor of survival. A case load of 40 patients per year per hospital appeared beneficial for survival.

A direct international comparison of trauma centers has not yet been described in the literature. Nevertheless, similar mortality rates have been published for comparable patient populations in the USA and the Netherlands [36].

In our opinion, the approximation of the lethality rates in both groups is above all due to advances in intensive care treatment for patients with thoracic trauma over the past years: Nowadays, lung-protective, non-invasive ventilation protocols and early extubation are used to avoid ventilation induced lung injuries [7]. The early use of spontaneous breathing ventilation modalities is associated with a shorter duration of ventilatory support and a reduced length of intensive care unit (ICU) stay [8]. Moreover, non-invasive ventilation modalities reduce reintubation rates and are useful in case of an acute respiratory distress syndrome (ARDS) caused by a thoracic trauma [9]. The use of an extracorporeal membrane oxygenation (ECMO) can improve the treatment and outcome of severely injured patients, including circumstances such as hemorrhagic shock [10]. The ECMO also achieves a considerable improvement of $\mathrm{paO}_{2} / \mathrm{FiO}_{2}$-ratio, $\mathrm{pH}$-levels and $\mathrm{pCO}_{2}$ [37]. As well as these treatment concepts, there are other medical achievements, which can improve the outcome of patients with a thoracic trauma, e.g. modern operative stabilization techniques of flail thoracic injuries [11] or the renaissance of prone positioning in ARDS [12].

In both groups, less patients died than expected by RISC II, the SMR was 0.66 in the severe thoracic trauma and 0.80 in the mild thoracic trauma group without significance difference. This finding was unexpected, especially the considerably lower SMR in the STT group. An explanation for this could be the significantly higher number of severe head injuries and the slightly older population in the MTT Group. Further studies on this topic will be necessary.

The severe thoracic trauma was not an independent predictor for lethality in the multivariable analysis. Similarly to previously published data, in our collective massive transfusion, an age over 60 years and GCS $<9$ were found to be independent risk factors for lethality $[24,38,39]$.

Also, the second multivariable analysis - based on injury pattern - does not unmask thoracic trauma as a risk for death. Brain and abdominal injuries could be detected to be responsible for lethality.

Through comparing our results with previously published data we can assume that modern treatment strategies (e.g. lung protective ventilation; prone positioning; ECMO) could have a positive influence on the mortality rate and the overall outcome of multiple injured patients with a severe thoracic trauma.

\section{Limitations}

Despite a big and precisely defined patient collective some limitations of the present study should be noted: Firstly, despite the prospective data collection, it is a register study with the known-weaknesses. Secondly, it is a single-center-study without the possibility to transfer the results to a general population. However, we do assume, that our therapy standards for preclinical, trauma room and ICU treatment (this includes ATLS/S3 guidelines) are comparable to other level-I trauma centers in Germany/high-income countries.

Further studies are needed to evaluate the influence of different treatment methods on the outcome of multiple injured patients with a severe thoracic trauma.

\section{Conclusions}

In contrast to prior studies, we show that in our study population the severe thoracic trauma has no direct influence on lethality in multiple injured patients. Patients who suffered a severe thoracic trauma still present a higher injury severity, an extended need of preclinical 
procedures and a higher rate of complications, but no difference in lethality in comparison to patients with a mild thoracic trauma. Further reduction of the lethality rate and a reduction of the complication rate should be a goal for the next decades.

\section{Abbreviations}

$\varnothing$ : Mean value; AIS: Abbreviated Injury Scale; ARDS: Acute respiratory distress syndrome; $\mathrm{Cl}$ : Confidence interval; $\mathrm{CO}_{2}$ : Carbon dioxide; $\mathrm{CT}$ : Computer tomography; CVC: Central venous catheter; DGU: Deutsche Gesellschaft für Unfallchirurgie e.V.; ECMO: Extracorporeal membrane oxygenation; GCS: Glasgow Coma Scale; GOS: Glasgow Outcome Score; Hb: Hemoglobin: ICU: intensive care unit; ISS: Injury Severity Score; MTT: Mild thoracic trauma NISS: New Injury Severity Score; OR: odds ratio; $\mathrm{paO}_{2} / \mathrm{FiO}_{2}$ : Partial pressure arterial oxygen / fraction of inspired oxygen; PTT: Partial thromboplastin time; RBT: Red blood cells transfusion; RISC II: Revised Injury Severity Classification II; RR: Blood pressure; SMR: Standardized mortality rate; STT: Severe thoracic trauma; WBMS-CT: Whole-Body-Multislice-CT

\section{Acknowledgements}

The publication of this work was supported by the German Research Foundation (DFG) within the funding program Open Access Publishing. We would also like to thank Esther Kiszler (Departement of Trauma Surgery, University Medical Center Regensburg), for language editing.

\section{Funding}

Not applicable

\section{Availability of data and materials}

Not applicable

\section{Authors' contributions}

Participated in the idea, planning, data analysis and interpretation, statistical analysis and writing the manuscript: MG, AE. Participated in data interpretation and writing the manuscript: MG, MK, AE. Participated in data acquisition: MG, ED, KA, AE. Have read and approved the final version: $M G$, $M K, E D, K A, M N$, AE. All authors read and approved the final manuscript.

\section{Ethics approval and consent to participate}

The study has been approved by the Institutional Review Board of the University of Regensburg (Number 14-101-0004). Data anonymity is guaranteed.

\section{Consent for publication}

Not applicable.

\section{Competing interests}

The authors declare that they have no competing interests.

\section{Publisher's Note}

Springer Nature remains neutral with regard to jurisdictional claims in published maps and institutional affiliations.

\section{Received: 8 August 2017 Accepted: 22 December 2017}

Published online: 08 January 2018

\section{References}

1. WHO Library Cataloguing-in-Publication Data. The global burden of disease: 2004 update. (NLM classification: W 74) @ World Health Organization 2008 ISBN 978924 1563710. http://www.who.int/healthinfo/global_burden_disease/ GBD_report_2004update_full.pdf.

2. Baker SP, O'Neill B, Haddon W JR., Long WB. The injury severity score. J Trauma Injury, Infection, Critical Care. 1974;14:187-196.

3. Timm A, Maegele M, Lefering R, Wendt K, Wyen $\mathrm{H}$, TraumaRegister DGU $\left.{ }^{(}\right)$. Pre-hospital rescue times and actions in severe trauma. A comparison between two trauma systems: Germany and the Netherlands. Injury. Elsevier; 2014;45 Suppl 3:S43-52.
4. Clark GC, Schecter WP, Trunkey DD. Variables affecting outcome in blunt chest trauma: flail chest vs. pulmonary contusion. J Trauma. 1988; 28:298-304.

5. Regel G, Sturm JA, Friedl HP, Nerlich M, Bosch U, Tscherne H. Significance of lung contusion in mortality following polytrauma. Possibilities for therapeutic influence. Chirurg. 1988;59:771-6.

6. Gaillard M, Hervé C, Mandin L, Raynaud P. Mortality prognostic factors in chest injury. J Trauma. 1990;30:93-6.

7. Spieth PM, Koch T, Gama de Abreu M. Approaches to ventilation in intensive care. Dtsch Arztebl Int. 2014;111:714-20.

8. Putensen C, Zech S, Wrigge H, Zinserling JR, Stüber F, von Spiegel T, Mutz N. Long-term effects of spontaneous breathing during Ventilatory support in patients with acute lung injury. Am J Respir Crit Care Med. 2001;164:43-9.

9. Chiumello D, Coppola S, Froio S, Gregoretti C, Consonni D. Noninvasive ventilation in chest trauma: systematic review and meta-analysis. Intensive Care Med. 2013:39:1171-80.

10. Arlt M, Philipp A, Voelkel S, Rupprecht L, Mueller T, Hilker M, Graf B, Schmid C. Extracorporeal membrane oxygenation in severe trauma patients with bleeding shock. Resuscitation. 2010;81:804-9.

11. Bottlang M, Long WB, Phelan D, Fielder D, Madey SM. Surgical stabilization of flail chest injuries with MatrixRIB implants: a prospective observational study. Injury. 2013:44:232-8.

12. Guérin $C$, Reignier J, Richard J-C, Beuret P, Gacouin A, Boulain T, et al. Prone positioning in severe acute respiratory distress syndrome. N Engl J Med. 2013;368:2159-68.

13. TraumaRegister DGU॰ 20 years TraumaRegister DGU॰: Development, aims and structure. Injury; 2014;45 Suppl 3:S6-S13.

14. States JD. The Abbreviated and the Comprehensive Research Injury Scales. STAPP. 400 Commonwealth Drive, Warrendale, PA, United States: SAE International; 1969. p. 690810.

15. TraumaRegister DGU`. Annual Report 2017. Available from: http://www. traumaregister-dgu.de/fileadmin/user_upload/traumaregister-dgu.de/docs/ Downloads/TR-DGU_Annual_Report_2017.pdf

16. German trauma society. Whitebook. $2^{\text {nd }}$ revised and updated edition. Recommendations on structure, organization, installations and equipment to promote quality, safety and reliability in the medical care of the severely injured in the Federal Republic of Germany. Georg Thieme Verlag, 2012.

17. Ruchholtz S, Lewan U, Debus F, Mand C, Siebert H, Kuhne CA. TraumaNetzwerk DGU๑: optimizing patient flow and management. Injury. 2014;45(Suppl 3):S89-92.

18. Teasdale G, Jennett B. Assessment of coma and impaired consciousness. A practical scale. Lancet. 1974;2:81-4.

19. Osler T, Baker SP, Long W. A modification of the injury severity score that both improves accuracy and simplifies scoring. J Trauma Injury, Infection, Critical Care. 1997;43:922-6.

20. Jennett B, Bond M. Assessment of outcome after severe brain damage. Practical Scale Lancet. 1975;305:480-4.

21. Lefering R, Huber-Wagner S, Nienaber U, Maegele M, Bouillon B. Update of the trauma risk adjustment model of the TraumaRegister DGU'm: the Revised Injury Severity Classification, version II. Crit Care. 2014;18:476.

22. Bayer J, Lefering R, Reinhardt S, Kühle J, Südkamp NP, Hammer T, Traumaregister DGU. Severity-dependent differences in early management of thoracic trauma in severely injured patients - Analysis based on the TraumaRegister DGU®. Scand J Trauma Resusc Emerg Med. 2017:25:10.

23. Hill $A B$, Fleiszer DM, Brown RA. Chest trauma in a Canadian urban settingimplications for trauma research in Canada. J Trauma. 1991;31:971-3.

24. Kulshrestha P, Munshi I, Wait R. Profile of chest trauma in a level I trauma center. J Trauma. 2004:57:576-81.

25. Champion HR, Copes WS, Sacco WJ, Lawnick MM, Keast SL, Bain LW, et al. The major trauma outcome study: establishing national norms for trauma care. J Trauma. 1990;30:1356-65.

26. Kleber C, Lefering R, Kleber AJ, Buschmann CT, Bail HJ, Schaser KD, Haas NP, DGU TraumaRegister. [Rescue time and survival of severely injured patients in Germany]. Unfallchirurg. Springer-Verlag; 2013;116:345-350.

27. Bardenheuer M, Obertacke U, Waydhas C, Nast-Kolb D, AG Polytrauma de DGU. Epidemiologie des Schwerverletzten. Eine prospektive Erfassung der präklinischen und klinischen Versorgung. Unfallchirurg. Springer-Verlag: 2000;103:355-363

28. Andruszkow H, Schweigkofler U, Lefering R, Frey M, Horst K, Pfeifer R, Kurt Beckers S, Pape H-C, Hildebrand F. Impact of Helicopter Emergency Medical 
Service in Traumatized Patients: Which Patient Benefits Most? Burney RE, editor. PLoS ONE; 2016;11:e0146897.

29. Huber S, Biberthaler P, Delhey P, Trentzsch H, Winter H, van Griensven M, Lefering $R$, Huber-Wagner S. Predictors of poor outcomes after significant chest trauma in multiply injured patients: a retrospective analysis from the German Trauma Registry (Trauma Register DGU®). Scand I Trauma Resusc Emerg Med. 2014;22:52.

30. Trupka A, Nast-Kolb D, Schweiberer L. Blunt chest trauma. Unfallchirurg Springer-Verlag. 1998;101:244-58.

31. Regel G, Lobenhoffer P, Grotz M, Pape HC, Lehmann U, Tscherne H. Treatment results of patients with multiple trauma. J Trauma Injury, Infection, Critical Care. 1995;38:70-8.

32. Ruchholtz S, Lefering R, Paffrath $\mathrm{T}$, Oestern $\mathrm{H}-\mathrm{J}$, Neugebauer E, Nast-Kolb D, Pape HC, Oestern HJ. Reduction in mortality of severely injured patients in Germany. Dtsch Arztebl Int. 2008;105:225-31.

33. Mefire AC, Pagbe JJ, Fokou M, Nguimbous JF, Guifo ML, Bahebeck J. Analysis of epidemiology, lesions, treatment and outcome of 354 consecutive cases of blunt and penetrating trauma to the chest in an African setting. S Afr J Surg. 2010;48:90-3.

34. Veysi VT, Nikolaou VS, Paliobeis C, Efstathopoulos N, Giannoudis PV. Prevalence of chest trauma, associated injuries and mortality: a level I trauma centre experience. Int Orthop. 2009;33:1425-33.

35. Zacher MT, Kanz K-G, Hanschen M, Häberle S, van Griensven M, Lefering R, Bühren V, Biberthaler P, Hubner-Wagner S. Association between volume of severely injured patients and mortality in German trauma hospitals. BJS. 2015;102:1213-9.

36. Dijkink S., Wilden G. van der Krijnen P., Dol L., Rhemrev S., King D., DeMoya M., Velmahos G., Schipper I. Polytrauma patients in the Netherlands and the USA: A bi-institutional comparison of processes and outcomes of care, Injury 2017.

37. Madershahian N, Wittwer T, Strauch J, Franke UFW, Wippermann J, Kaluza M. Wahlers. T. Application of ECMO in multitrauma patients with ARDS as rescue therapy. J Card Surg. 2007;22:180-4.

38. Johnson JA, Cogbill TH, Winga ER. Determinants of outcome after pulmonary contusion. J Trauma. 1986;26:695-7.

39. Huber-Wagner S, Qvick M, Mussack T, Euler E, Kay MV, Mutschler W, Kanz KG, DGU. Massive blood transfusion and outcome in 1062 polytrauma patients: a prospective study based on the trauma registry of the German trauma society. Vox sang. 7 ed. Blackwell Publishing Ltd. 2007;92:69-78.

\section{Submit your next manuscript to BioMed Central and we will help you at every step:}

- We accept pre-submission inquiries

- Our selector tool helps you to find the most relevant journal

- We provide round the clock customer support

- Convenient online submission

- Thorough peer review

- Inclusion in PubMed and all major indexing services

- Maximum visibility for your research

Submit your manuscript at www.biomedcentral.com/submit 